\title{
Kaolin Bleaching by Leaching Using Phosphoric Acid Solutions
}

\author{
Román A. Hernández Hernández, ${ }^{1 *}$ Felipe Legorreta García, ${ }^{1}$ Leticia E. Hernández Cruz, ${ }^{1}$ \\ Arnoldo Bedolla Jacuinde ${ }^{2}$ \\ ${ }^{1}$ Universidad Autónoma del Estado de Hidalgo, Área Académica de Ciencias de la Tierra y Materiales. \\ Carretera Pachuca-Tulancingo, Km 4.5 s/n, Mineral de la Reforma, Hgo., México, C.P. 42184. \\ ${ }^{2}$ Universidad Michoacana de San Nicolás de Hidalgo, Instituto de Investigaciones Metalúrgicas. Av. Francisco J. Mujica S/N \\ Ciudad Universitaria, Morelia, Michoacán, México, C.P. 58000. \\ *angelitofox3@hotmail.com
}

Received October $3^{\text {rd }}, 2013$; Accepted August $20^{\text {th }}, 2015$.

\begin{abstract}
This paper presents a study of kaolin ore bleaching from the municipality of Agua Blanca of Iturbide, Hidalgo, México. This process was carried out using solutions of phosphoric acid as the leaching reagent for the iron dissolution process. It is well known that iron oxide is the major contaminant of clay minerals and silicate used in industry. These contents should be decreased, usually by $0.1 \%$, to achieve a required whiteness index of $90 \%$ (ISO) or higher. The whitening improves its economic value, making it possible to use it as a high-quality raw material in industries such as ceramics and paper. For this purpose, we examined the effect of parameters such as the concentration of the leaching reagent $(0.10 \mathrm{M}, 0.50 \mathrm{M}, 1 \mathrm{M}$, and $3 \mathrm{M})$, temperature (298-373 K), and $\mathrm{pH}$ level (1, 2 and 3). The experimental results showed that the studied variables have a great influence over the ability to obtain an iron dissolution percentage of more than $98 \%$ after 2 hours and $373 \mathrm{~K}$.
\end{abstract}

Key words: Leaching, Phosphoric acid, Kaolin, Iron.

\section{Introduction}

The term kaolin is used to refer to white clays, whereby the principal mineral is kaolinite $\left(\mathrm{Al}_{2} \mathrm{Si}_{2} \mathrm{O}_{5}(\mathrm{OH})_{4}\right)$. The Kaolin particles are usually hexagonal and $0.05-10 \mu \mathrm{m}$ in diameter $(0.5$ $\mu \mathrm{m}$ on average). Since this mineral is a product of the decomposition of feldspars and micas present in pegmatite micaceous schist, it is usually accompanied by other minerals such as quartz, sulfur, feldspars, micas, and iron and titanium oxides, among others $[1,2]$. The main uses of kaolin are: paper filling and coating (45\%); refractories and ceramics (31\%); fiberglass $(6 \%)$; cement $(6 \%)$; rubber and plastic $(5 \%)$; paint $(3 \%)$; and others $(4 \%)$ [3].

Iron is the main contaminant in clay and kaolin minerals. In fact, the presence of this impurity in these minerals lowers their economic value and makes it impossible to use them in numerous traditional (i.e., the production of ceramic products and paper) and more advanced applications. The high quality of these industrial minerals is generally obtained via physical or chemical processes.

When one considers that conventional processes do not succeed in removing the aforementioned metal, it is under-
Resumen. En este trabajo se presenta un estudio para el blanqueo de mineral de caolín del municipio de Agua Blanca de Iturbide, Hidalgo (México), que se llevó a cabo utilizando soluciones de ácido fosfórico como reactivo de lixiviación para el proceso de disolución de hierro. Se sabe que el óxido de hierro es el principal contaminante de minerales arcillosos y silicatos utilizados en la industria. Estos contenidos se deben disminuir, por lo general $0.1 \%$ para alcanzar un índice de blancura requerida de $90 \%$ (ISO) o superior. Su blanqueamiento mejora el valor económico que le da la posibilidad de ser utilizados como materia prima de alta calidad en industrias como la cerámica y papel. Por esta razón hemos estudiado el efecto de los parámetros tales como concentración del reactivo de lixiviación $(0.10 \mathrm{M}, 0.50 \mathrm{M}, 1 \mathrm{M}$ y $3 \mathrm{M})$, temperatura $\left(25\right.$ a $\left.100{ }^{\circ} \mathrm{C}\right)$ y el $\mathrm{pH}(1,2$ y 3$)$. Los resultados experimentales mostraron que las variables estudiadas tienen gran influencia en la obtención del porcentaje de disolución de hierro de más de $98 \%$ después de $2 \mathrm{~h}$ y temperatura de $100{ }^{\circ} \mathrm{C}$.

Palabras clave: Lixiviación, Ácido fosfórico, Caolín, Hierro.

standable that numerous studies have focused on improving the dissolution process. These studies are generally carried out on synthetic iron oxide and, therefore, they do not consider the interactions with nonferrous minerals (for example, they do not take into consideration the presence of encapsulated iron), which cause a significant change in the dissolution process kinetics.

Several physical and chemical processes, such as sieving, magnetic separation [4], selective flocculation [5], leaching with chemicals like oxalic and other organic acids [6-11], organic acids in the presence of a fermented medium [12], leaching containing microbial-produced oxalic and hydrochloric acid [13], EDTA [14], sodium dithionate- $\mathrm{H}_{2} \mathrm{SO}_{4}$ mixtures [15], and so on, have been employed to lower the content of these impurities in the kaolin clays.

In this study, the application of phosphoric acid to bleach kaolin clays is reported for the first time. Furthermore, the residual solutions that have formed can be used to manufacture ceramics [16]; this is the primary reason why, in this paper, we elected to present the results we obtained once we tested the efficiency of $\mathrm{H}_{3} \mathrm{PO}_{4}$ when purifying kaolin clays. Furthermore, we also sought to optimize the process parameters, while exam- 
ining the effects of temperature, $\mathrm{pH}$, and concentration of the leaching agent on the recuperation percentages to obtain mineral kaolin with low iron contents.

\section{Experiment}

\section{Reagents and Materials}

The kaolin mineral sample was obtained from Agua Blanca Iturbide (Hidalgo, México), which had been previously reduced in size and classified by ASTM mesh. A complete chemical analysis by atomic absorption spectrophotometry is shown in Table 1. The iron content in the mineral was $0.70 \% \pm 0.01 \%$, reported as $\mathrm{Fe}_{2} \mathrm{O}_{3}$. Mineral particles with an average size of 35 $\mu \mathrm{m}$ were used in the leaching experiment. Phosphoric acid (reagent grade; J.T. Baker, Center Valley, PA, USA) was used as a leaching agent. The leaching system that was used consisted of a heating mantle, a $500 \mathrm{~mL}$ Pyrex glass reactor with a condenser, and magnetic stirring. A centrifuge was used (Model 228; Thermo Fisher Scientific, Waltham, MA, USA) for solid-liquid separation of the sample that was collected to quantify the dissolved iron. Iron was quantified using atomic absorption spectrophotometry (Optima 3000 XL; Perkin Elmer Inc., Waltham, MA, USA). To determine the mineral species present in the kaolin samples, X-ray diffraction patterns were determined using an Equinox 2000 diffractometer (I.N.E.L. Instrumentation Electronique, Artenay, France), with $\mathrm{Cu} \mathrm{K} \alpha$ radiation at $40 \mathrm{kV}$ and $40 \mathrm{~mA}$.

\section{Experiment design}

The leach solution was prepared by mixing known amounts of phosphoric acid $\left(\mathrm{H}_{3} \mathrm{PO}_{4}\right.$, reagent grade) with distilled water. Sulfuric acid was slowly added to adjust the $\mathrm{pH}$ to the required value. The liquor (volume $400 \mathrm{~mL}$ ) was then transferred to a round flask (capacity: $0.50 \mathrm{~L}$ ); to obtain different temperatures before adding the clay sample ( $40 \mathrm{~g}$ ), a heating mantle controlled by a thermostat was used. The kaolin was suspended by

Table 1. Chemical Analysis of the kaolin sample.

\begin{tabular}{cc}
\hline Components & \% Weight \\
\hline $\mathrm{SiO}_{2}$ & 54.30 \\
$\mathrm{Al}_{2} \mathrm{O}_{3}$ & 43.10 \\
$\mathrm{Fe}_{2} \mathrm{O}_{3}$ & 0.700 \\
$\mathrm{CaO}$ & 0.004 \\
$\mathrm{MgO}$ & 0.006 \\
$\mathrm{Na}_{2} \mathrm{O}$ & 0.265 \\
$\mathrm{~K}_{2} \mathrm{O}$ & 0.349 \\
$\mathrm{TiO}_{2}$ & 0.418 \\
$\mathrm{LIO}^{*}$ & 0.950 \\
\hline
\end{tabular}

LIO* = Lost on Ignition. magnetic stirring. In the leaching tests at $373 \mathrm{~K}$, the reactor was equipped with a thermometer and a reflux condenser. All leaching tests were carried out at atmospheric pressure. Each reaction was conducted for $2 \mathrm{~h}$ and samples were taken out at 5, 15, 30, 60, 90, and $120 \mathrm{~min}$ for iron analysis. For each sample, 10 $\mathrm{mL}$ of liquor was withdrawn from the reactor into a $25 \mathrm{~mL}$ volumetric flask. This sample was vacuum filtered and then immediately centrifuged at $300 \mathrm{rpm}$ for $15 \mathrm{~min}$. A $5 \mathrm{~mL}$ aliquot of clear solution was collected to determine the total iron concentration. The analysis was performed using atomic absorption spectrometry. The solution $\mathrm{pH}$ level was controlled at a $\mathrm{pH}$ of $1.0,2.0$, or 3.0 using sulfuric acid. Experiments were performed in duplicate. The variables studied were the concentration of phosphoric acid, $\mathrm{pH}$, and temperature.

\section{Results and discussion}

\section{Mineralogical Analysis}

$\mathrm{X}$-ray diffraction analysis revealed the nature of the crystalline phases present in the mineral, as shown in Fig. 1. The study sample is mainly constituted by the kaolinite mineral with minor silica contributions, which were also detected as quartz and tridymite. Iron is considered to be an impurity and it is present as magnetite $\left(\mathrm{Fe}_{3} \mathrm{O}_{4}\right)$, hematite $\left(\mathrm{Fe}_{2} \mathrm{O}_{3}\right)$, titanium oxide-ferrous $\left(\mathrm{Fe}_{2} \mathrm{TiO}_{4}\right)$, and greigite $\left(\mathrm{Fe}_{3} \mathrm{~S}_{4}\right)$.

A decrease in the peaks that correspond to magnetite and hematite was also shown for (a) natural kaolin mineral and (b) leached kaolin; according to this finding, we can observe that during the leaching process, it is possible to reduce the iron content.

\section{Effect of Acid Concentration}

To observe the effect of different phosphoric acid concentrations of $0.10,0.50,1.0$, and $3.0 \mathrm{M}$, experiments were performed

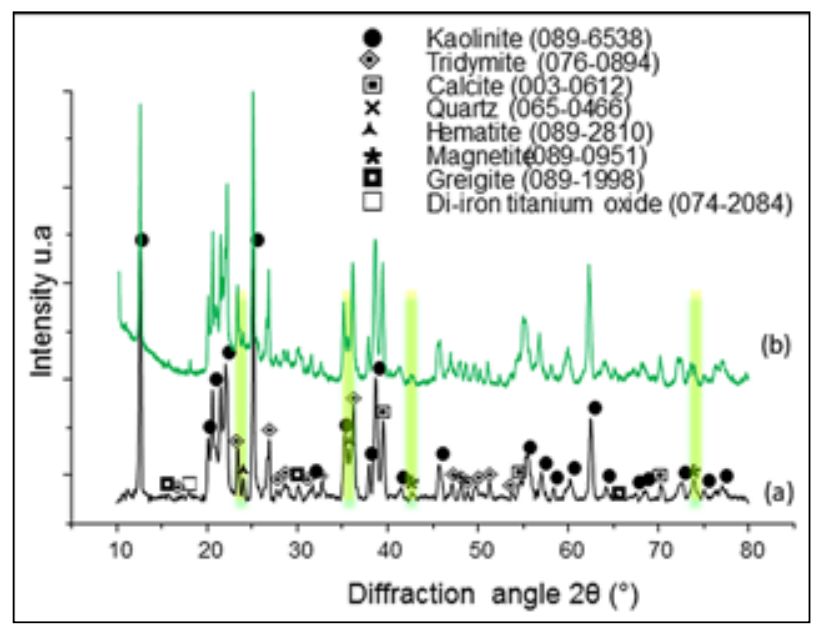

Fig. 1. X-ray diffractogram of: a) kaolin mineral and (b) leached kaolin. 
in the range of $298-373 \mathrm{~K}$ at a $\mathrm{pH}$ level of 1. Fig. 2 shows that increasing the phosphoric acid concentration increase the iron dissolution rate from kaolin clay. It was also observed that the iron leaching rate at $1.0 \mathrm{M}$ is higher than at $0.10 \mathrm{M}$, where the iron dissolution rates were $98.65 \%$ and $19.81 \%$, respectively. It was also observed that the curves showed (see Fig. 2) for 1.0 $\mathrm{M}$ and 3.0 $\mathrm{M}$ presented similar behavior trends and iron dissolution rates from the kaolin clays. Thus, we can conclude that this concentration range no longer affects the kinetics above $1.0 \mathrm{M}$ at these conditions.

The results found in this study are also in accordance with those of another study [17], which reported a high efficiency rate of iron removal; however, unlike the methods used in this work, the other study was carried out on quartz sand using phosphoric acid.

Hydrogen ions play an important role in the dissolution of iron oxides with inorganic acids. $\mathrm{H}_{3} \mathrm{PO}_{4}$ in solution provides $\mathrm{H}^{+}$, which reacts with iron oxide; the possible reaction according to Zhizhen et al [17] might be:

$$
6 \mathrm{H}^{+}+\mathrm{Fe}_{2} \mathrm{O}_{3} \rightarrow 2 \mathrm{Fe}^{3+}+\mathrm{H}_{2} \mathrm{O}
$$

These hydrogen ions are absorbed on the surface by activating the iron mineral particle surface. The hydrogen ions are adsorbed on sites on the solid surface, creating surface-active centers on which the main reaction for dissolution takes place. According to adsorption theory, as the hydrogen ion concentration in the solution increases, the amount of adsorbed hydrogen ions also increases. An increase in the number of active centers results in a corresponding increase in the dissolution rate [14].

$\mathrm{H}_{3} \mathrm{PO}_{4}$ does not only provide more $\mathrm{H}^{+}$ions $\left(\mathrm{PK}_{\mathrm{al}}=2.12\right.$, where $\mathrm{a}_{1}=$ first dissociation $\mathrm{H}^{+}$), which will react with iron oxide, but the $\mathrm{PO}_{4}{ }^{3-}$ ions that are produced during the course of $\mathrm{H}^{+}$ionization also have a larger complexing ability toward iron ions. All of these features constitute the highest leaching percentages of $\mathrm{H}_{3} \mathrm{PO}_{4}$.

The possible reaction according Zhizhen et al [17] is the following:

$$
\begin{aligned}
& 8 \mathrm{H}^{+}+4 \mathrm{PO}_{4}^{3-}+\mathrm{Fe}_{2} \mathrm{O}_{3} \rightarrow\left[\mathrm{Fe}\left(\mathrm{HPO}_{4}\right)_{2}\right]^{-}+ \\
& {\left[\mathrm{Fe}\left(\mathrm{PO}_{4}\right)_{2}\right]^{3-}+3 \mathrm{H}_{2} \mathrm{O}}
\end{aligned}
$$

Moreover, Al-Sogair et al [18, 19] proposed the following reactions of iron with phosphoric acid:

$$
\begin{aligned}
& \mathrm{Fe}^{3+}+\mathrm{H}_{3} \mathrm{PO}_{4} \leftrightarrow \mathrm{FeH}_{2} \mathrm{PO}_{4}^{2+}+\mathrm{H}^{+} \\
& \mathrm{Fe}^{2+}+\mathrm{H}_{3} \mathrm{PO}_{4} \leftrightarrow \mathrm{FeH}_{2} \mathrm{PO}_{4}^{+}+\mathrm{H}^{+}
\end{aligned}
$$

The iron content in the kaolin analysis that was performed after $2 \mathrm{~h}$ was $0.004 \mathrm{~g}$, as determined by traditional metallurgical balance and atomic absorption spectrophotometry. The iron conversion was as follows: the reaction (1) takes place during iron dissolution. First, phosphoric acid dissociation occurs; following that, the dissolution of iron in the ore. Subsequently,

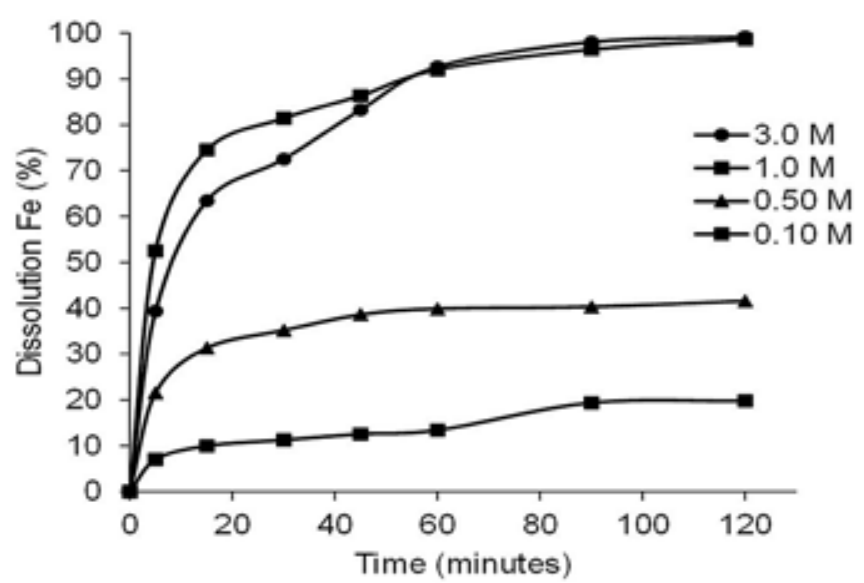

Fig. 2. Effect of phosphoric acid concentration on Fe dissolution from kaolin clay at $373 \mathrm{~K}, \mathrm{pH} 1.0$.

the formation of different iron phosphate complexes occurs, according to reactions (2), (3), and (4). These multiple synergisms of $\mathrm{H}_{3} \mathrm{PO}_{4}$ yield the best leaching results. The phosphate anion constitutes an important part of the mechanism [20]. The phosphate anion reacts strongly with both ferric and ferrous ion complexes, to such an extent that iron phosphates are only soluble when the anion is not completely dissociated. This is the principal reason for the successful bleaching of kaolin by phosphoric acid.

\section{Effect of Reaction Temperature}

In order to study the effect of temperature on iron dissolution, several experiments were carried out in the temperature range of 298-373 K in $1.0 \mathrm{M}$ phosphoric acid solutions with a constant $\mathrm{pH}$ of 1 . The typical rate curves are shown in Fig. 3. From this figure, it can be seen that the dissolution rate is highly sensitive to the reaction temperature. It can also be observed that the iron dissolution was very slow at temperatures in the range of $273-313 \mathrm{~K}$, but this rate increased rapidly above $333 \mathrm{~K}$. This indicates that a reasonable reaction rate can only be achieved at temperatures above $353 \mathrm{~K}$. Therefore, iron dissolution using phosphoric acid could be thermally activated to improve the efficiency of this process.

\section{Effect of pH}

The effect of $\mathrm{pH}$ was studied through a series of tests performed at $373 \mathrm{~K}$ in a $3.0 \mathrm{M}$ phosphoric acid solution and with $\mathrm{pH}$ values varying between 1 and 3 . The results are presented in Fig. 4. The rate of iron dissolution is significantly affected by $\mathrm{pH}$. The optimum dissolution rate is observed at a $\mathrm{pH}$ level of 1 , whereas in less acidic solutions, the dissolution rate decreases.

To better explain the effect of $\mathrm{pH}$ on iron dissolution and the corresponding reactions, we developed distribution diagrams for $\mathrm{Fe}^{2+}$ and $\mathrm{Fe}^{3+}$ (see Figs. 5 and 6, respectively) using the Medusa software program (Chemical Equilibrium Dia- 


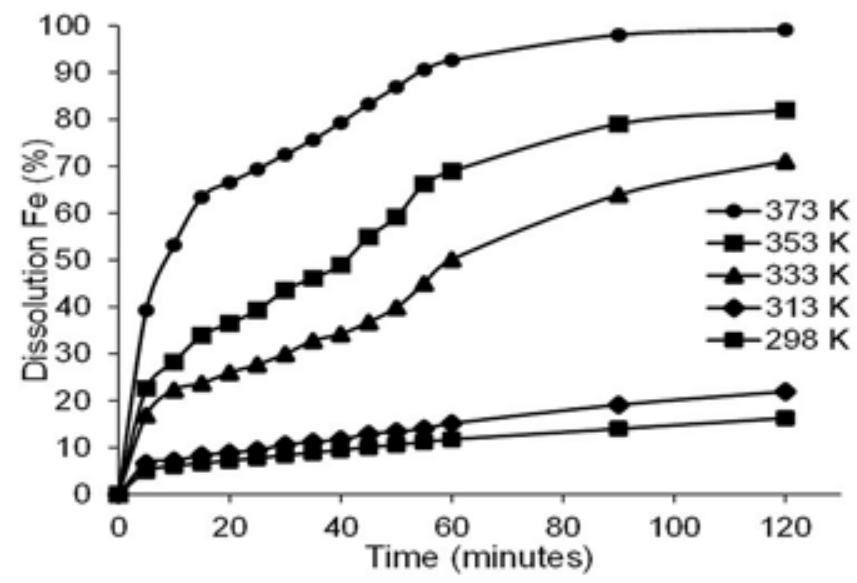

Fig. 3. Effect of temperature on Fe dissolution from kaolin clays, 1.0 M phosphoric acid, $\mathrm{pH} 1.0$.

grams). Due to the lack of equilibrium data for other temperatures, we presented the diagrams at $298 \mathrm{~K}$. The phosphate anion strongly complexes both ferric and ferrous ions; nevertheless, the iron phosphates are only soluble when the anion is not completely dissociated $(\mathrm{pH}<2$ and 4 for ferric and ferrous ions, respectively). This is the principal reason behind the successful bleaching of kaolin with phosphoric acid.

As stated above, increased temperature favors both iron dissolution and the formation of complexes (iron phosphate). When the kaolin mineral is added to a phosphoric acid solution, $\mathrm{pH}$ affects the speciation in the solution. In strong acid solutions ( $\mathrm{pH} 1.0$ ), the ferric iron ions are complexed as $\left[\mathrm{FeH}_{2} \mathrm{PO}_{4}^{2+}\right]$ (eq. 3), and as the $\mathrm{pH}$ level increases, the amount of these complex ions in the solution begins to decrease. Furthermore, with $\mathrm{pH}$ values higher than 2.0, most of the iron ions are in the form of solid $\left[\mathrm{FeHPO}_{4}^{-}: 2 \mathrm{H}_{2} \mathrm{O}\right.$ ], which is when water-insoluble tertiary phosphates tend to precipitate. From the aforementioned findings, it can be deduced that the complexation of iron ions

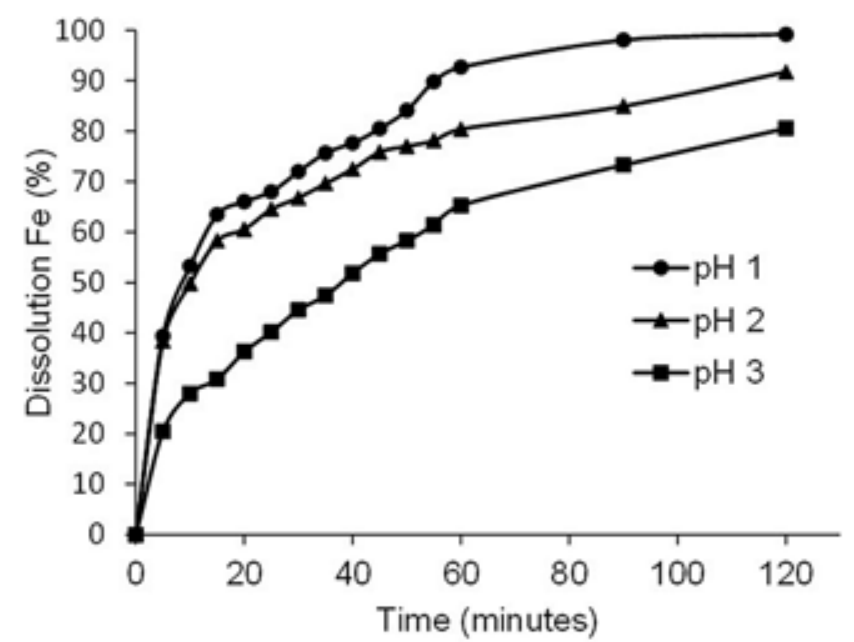

Fig. 4. Effect of $\mathrm{pH}$ on Fe dissolution from kaolin clays, 3.0 M phosphoric acid, $373 \mathrm{~K}$.

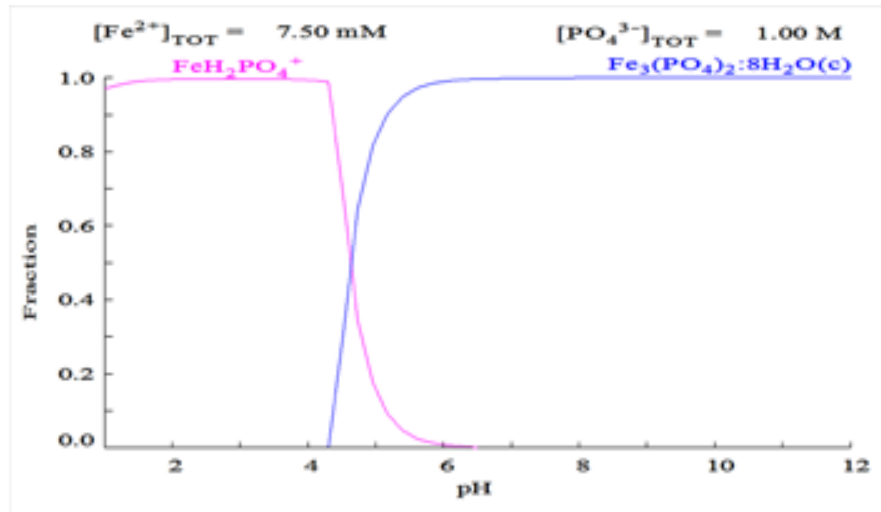

Fig. 5. Diagram species (Fe 7.5 mM) with 1.0 M phosphoric acid for $\mathrm{Fe}^{2+}$.

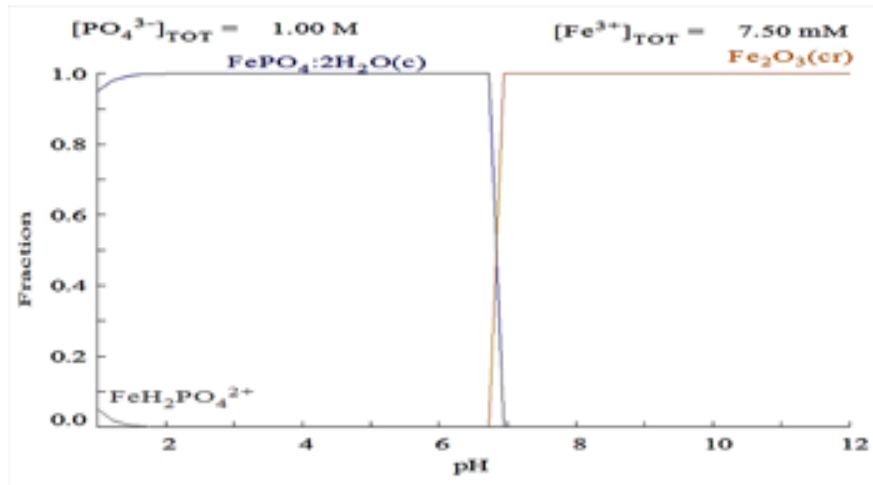

Fig. 6. Diagram species ( $\mathrm{Fe} 7.5 \mathrm{mM}$ ) with $1.0 \mathrm{M}$ phosphoric acid for $\mathrm{Fe}^{3+}$.

must occur in strong acid solutions. Experimentally, this is found at $\mathrm{pH}$ values around 1.0-1.5.

\section{Conclusions}

The application of phosphoric acid to bleaching kaolin clays is reported for the first time. The experimental results obtained in this study showed that phosphoric acid is one of the best leaching reagents in the purification of iron impurities from kaolin clays, particularly due to the properties of $\mathrm{H}_{3} \mathrm{PO}_{4}$ itself (it is very soluble in water, it acts as a chelating agent, and it dissociates at relatively low $\mathrm{pH}$ values). Also, the phosphate anion reacts strongly with complexes of both ferric and ferrous ions; this is the principal reason underlying the successful bleaching of kaolin with phosphoric acid. It was also observed that the leach rate is influenced by both $\mathrm{pH}$ level and the reaction temperature. To be effective above $353 \mathrm{~K}$, phosphoric acid must to be thermally activated. Moreover, the dissolution rate decreases with increasing $\mathrm{pH}$; this is due to the formation of $\left[\mathrm{FePO}^{4}\right.$ : $2 \mathrm{H}_{2} \mathrm{O}$ ], which tend to precipitate. The best conditions for removal of iron were found to be a temperature of $373 \mathrm{~K}$, a solid-to-liquid ratio of $10 \%$, kaolin clays with an average particle size of $35 \mu \mathrm{m}$ a $\mathrm{pH}$ of 1.0 , and a phosphoric acid concentration of $3.0 \mathrm{M}$. 


\section{References}

1. Avgustinik, A. In: Cerámica, Ed. Reverté S.A., Barcelona, 1983.

2. Norton, A. Cerámica Fina, Ed. Omega, Barcelona, 1983.

3. Murray, H. Min. Miner, 2002, 64, 1-9.

4. Shoumkov, S.; Dimitrov, Z.; Brakalov, L. Interceram, 1987, 36, 26-38.

5. Besraa, L.; Senguptaa, D.; Royb, S.; Ay, P. International Journal of Mineral Processing, 2002, 66, 203-232.

6. Lee, S.; Tran, T.; Jung, B; Kim, S.; Kim, M. Hydrometallurgy, 2007, 87, 91-99.

7. Martínez-Luévanos, A.; Rodríguez-Delgado, M. G; Uribe-Salas, A.; Carrillo-Pedroza, F. R.; Osuna-Alarcón, J. G. Applied Clay Science, 2011, 51, 473-477.

8. Panias, D.; Taxiarchou, M.; Paspaliaris, I.; Kontopoulos, A. Hydrometallurgy, 1996, 42, 257-265.

9. Veglio, F.; Toro, L. Int. J. Miner. Process. 1993, 39, 87-99.

10. Legorreta-García, F.; Salinas-Rodríguez, E.; Hernández-Cruz, L. E.; Hernandez-Hernández, R.A.; Cerecedo Sáenz E.; European Scientific Journal., 2015, 11, 12-23.
11. De Mesquita, L.; Rodrigues, T.; Gomes, S. Miner. Eng., 1996, 9 , 965-971.

12. Hosseini,M.R., Ahmadi A. Applied Clay Science., 2015, revised version submitted for publication.

13. Groudev, S. Miner. Metall. Process., 1999, 16, 19-28.

14. Borggaard, O. J. Soil Sci., 1979, 30, 727-734.

15. Ambikadevi, V.R; Lalithambika, M. Applied Clay Science, 2000, 16, 133-145.

16. Arun, S.; Wagh, Y.; Seung, Y. Journal of the American Ceramic Society, 2003, 86, 1850-1855.

17. Zhizhen, Z.; Jingsheng, L.; Xiaoxia, L.; Houquan, H.; Lifen, Z.; Tiantian, X. International Journal of Mineral Processing, 2012, 114, 30-34.

18. Al-Sogair, F.; Marafie, H. M.; Shuaib, N. M.; Youngo, H. B.; El-Ezaby, M. S. J. Coord. Chem., 2002, 55, 1097-1109.

19. Ueshima, M.; Fortin, D.; Kalin, M. Geomicrobiology Journal, 2004, 21, 313-323.

20. Majima, H.; Awakura, Y.; Mishima, T.; Met. Trans. 1985, 16B, 23-30. 